\title{
HIV-1 promoter activation following an oxidative stress mediated by singlet oxygen
}

\author{
Legrand-Poels S[1][2], Hoebeke M[2], Vaira D[1], Rentier B[1] Piette J[1][2]
}

[1] Laboratory of Virology, Institute of Pathology B23,University of Liege, B-400 Liege (Belgium)

[2] Experimental Physics, Institute of Physics B5, University of Liege, B-400 Liege (Belgium)

\begin{abstract}
Various biological processes, such as photosensitization or inflammatory reactions, can generate singlet oxygen $\left({ }^{1} \mathrm{O}_{2}\right)$ as one of the major oxidative species. Because this oxidant can be generated either extracellularly or intracellularly, it can cause severe damage to various biological macromolecules, even to those deeply embedded inside the cells such as DNA. Sublethal biological modifications induced by different DNA-damaging agents can promote various cellular responses initiated by the activation of various cellular genes and certain heterologous viruses. Since ${ }^{1} \mathrm{O}_{2}$ fulfils essential prerequisites for a genotoxic substance, we have examined the effects of an oxidative stress, mediated by this species, on cells harbouring a heterologous promoter-leader sequence derived from the human immunodeficiency virus type 1 (HIV-1). Our results demonstrate that HIV-1 long terminal repeat (LTR), integrated into the cellular DNA of epithelial cells, can be transactivated following an oxidative stress mediated by ${ }^{1} \mathrm{O}_{2}$ In addition, using HIV-1 latently infected promonocytes or lymphocytes, it can be shown that virus reactivation can be induced through a sublethal dose of ${ }^{1} \mathrm{O}_{2}$ generated intracellularly. An extracellular generation of ${ }^{1} \mathrm{O}_{2}$ can promote a substantial lethal effect without HIV-1 reactivation. These data may be relevant to the understanding of the events converting a latent infection into a productive one and to the appearance of the acquired immune deficiency syndrome.
\end{abstract}

\section{Keywords}

HIV-1, singlet oxygen, promoter activation

\section{Introduction}

It is now well established that singlet oxygen ${ }^{1} \mathrm{O}_{2}$ is a major oxidative species which can be generated during numerous biological reactions, such as photosensitization [1, 2] or inflammatory processes [3]. Aerobes have evolved antioxidant defences against most reactive oxygen species (hy-droxyl radicals, superoxide anions, hydrogen peroxide and ${ }^{1} \mathrm{O}_{2}$ [4] and pathways to repair damage induced by these species to various biomolecules and particularly damage induced by ${ }^{1} \mathrm{O}_{2}$ to nucleic acids [5]. These general protection mechanisms include various enzymes, such as superoxide dis-mutase, catalase, glutathione peroxidase and DNA repair enzymes [6,7], low molecular weight agents, such as $\alpha$ tocopherol, $\beta$-carotene and ascorbic acid [8], and proteins that bind metal ions rendering them unable to accelerate free radical reactions [9]. When active oxygen species are not adequately removed, an oxidative stress situation appears in the cell resulting in major metabolic dysfunctions, such as membrane peroxidation, rise in intracellular free calcium ions, cytoskeletal disruption and DNA damage [10]. Concomitantly, various cellular genes are activated leading to a synthesis of several stress 
proteins, such as heat shock proteins, glucose-regulated proteins, haem oxygenase and metallothionine $[11,12]$.

${ }^{1} \mathrm{O}_{2}$ behaves like other oxygen reactive species because it can mediate the oxidation of major cellular molecules $[13,14]$. DNA, proteins and lipids are all at risk. The pattern of DNA modifications produced by ${ }^{1} \mathrm{O}_{2}$ is very different from that caused by other oxygen activated species such as hydroxyl radicals. Whereas hydroxyl radicals produce DNA strand breaks together with sites of base loss in high yield and react with all four bases of DNA, singlet oxygen generates predominantly modified guanine residues and few strand breaks $[14,15]$. When singlet oxygen is generated inside cells, it is very genotoxic leading to an important mutagenic effect $[16,17]$. Produced ex-tracellularly, it reacts with the lipids of the cellular membrane forming hydroperoxides which, in turn, can decompose to give several types of secondary lipid free radicals [18]. These lipid radicals can then participate in the propagation reactions of lipid peroxidation and DNA can be a further target [19]. Oxidation of these major cellular molecules leads to cell response with synthesis of oxidative stress proteins which may have several regulatory functions $[11,12]$.

Singlet oxygen is a genotoxic substance which can be produced in vivo, inside or outside cells. The aim of this work was to test whether oxidative stress, generated by this oxygen activated species, can lead to activation of a heterologous promoter, such as the human immunodeficiency virus type 1 (HIV-1) long terminal repeat (LTR), and to HIV-1 gene expression. This situation of oxidative stress is especially relevant to in vivo situations where HIV-1 latently infected T cells may be proximal to activated phagocytes during inflammatory reactions. Previous work from our laboratory has shown that oxidative stress produced by hydrogen peroxide can induce the reactivation of latent HIV-1 [20]. This virus predominantly infects T-helper cells, macrophages and monocytes [21]. Following penetration of these cells, its genome becomes integrated in cell chromosomes and the provirus can remain latent for several years. Proviral transcriptional activity is determined by the interplay of a series of constitutive and inducible transcription factors [22]. HIV-1 latency seems to result from inefficient proviral transcription due to a subcritical amount of regulatory proteins such as the virally encoded Tat and Rev proteins [23]. Factors triggering HIV-1 reactivation are those, such as cytokines, which achieve the increase in regulatory factors over a certain critical level to promote viral gene expression. Because inflammatory cytokines [24] and hydrogen peroxide [20, 25] have been shown to promote HIV-1 reactivation, we attempted to determine whether or not ${ }^{1} \mathrm{O}_{2}$ is capable of mediating $\mathrm{HIV}-1$ promoter activation and HIV-1 reactivation.

\section{Materials and methods}

\subsection{Established cell lines}

HeLa HIV-1 chloramphenicol acetyltransferase (CAT) line was supplied by Kris Valerie (SmithKline and French Laboratories, King of Prussia, USA) and was grown in Dulbecco's minimal essential medium (DMEM) containing 10\% foetal calf serum (FCS) and minimal essential amino acids. The promonocytic cell line Ul [26] and the lymphocytic cell line ACH-2 [27] were cultivated in RPMI1640 medium supplemented with $10 \%$ FCS.

\subsection{Exposure of HeLa HIV-1 CAT cells to ${ }^{1} \mathrm{O}_{2}$}

\subsubsection{Intracellular generation of ${ }^{1} \mathrm{O}_{2}$}

Exponentially growing HeLa HIV-1 CAT cells in $75 \mathrm{~cm}^{2}$ flasks (approximately 2 X $10^{6}$ cells) were washed twice with phosphate-buffered saline (PBS), covered with a solution of rose bengal (RB) [28], purified by gel chromatography [29] and dissolved in PBS (10 ml) at various concentrations. Before irradiation (Xe vapour lamp, Osram XBO-150, Germany, $\lambda>500 \mathrm{~nm}, 40 \mathrm{~W} \mathrm{~m}^{-2}$ ), the pho-tosensitizer was allowed to penetrate the cells for $10 \mathrm{~min}$ in the dark. The cells were irradiated, washed with fresh PBS and cultivated for $24 \mathrm{~h}$ in DMEM-FCS. The surviving cells were harvested and counted to be used for CAT activity determination. The relative errors on cell counts were estimated to be $\pm 20 \%$. 


\subsubsection{Extracellular generation of ${ }^{1} \mathrm{O}_{2}$ Extracellular production of ${ }^{1} \mathrm{O}_{2}$ was mediated}

by a photosensitization reaction with Sensitox II (Poly RB, Hydron Laboratories, USA) which corresponded to RB bound to beads [30]. This binding prevented the cellular uptake of RB, leading to extracellular generation of ${ }^{1} \mathrm{O}_{2}$. Exponentially growing HeLa HIV-1 CAT cells in $75 \mathrm{~cm}^{2}$ flasks (approximately $2 \times 10^{6}$ cells) were washed twice with PBS and then covered with $8.2 \mathrm{mg}$ of Sensitox 11 suspended in either $25 \mathrm{ml}$ of PBS with or without a quencher of ${ }^{1} \mathrm{O}_{2}(9,10$-anthracene dipropionic acid (ADPA), $80 \quad M$ [31] or in $25 \mathrm{ml}$ of PBS buffer prepared in $\mathrm{D}_{2} \mathrm{O}$. Substitution of $\mathrm{H}_{2} \mathrm{O}$ by $\mathrm{D}_{2} \mathrm{O}$ led to an increase in the ${ }^{1} \mathrm{O}_{2}$ lifetime, which is approximately tenfold greater in $\mathrm{D}_{2} \mathrm{O}$ than in $\mathrm{H}_{2} \mathrm{O}$ [32]. After irradiation with filtered light emitted by an Xe vapour lamp (Osram XBO-150, $\lambda>500 \mathrm{~nm}, 40 \mathrm{~W}$ $\mathrm{m}^{-2}$ ), cells were washed with fresh PBS and cultivated for $24 \mathrm{~h}$ in DMEM-FCS. The surviving cells were harvested and treated as mentioned above.

\subsection{Exposure of the Ul and ACH-2 cell lines to ${ }^{1} \mathrm{O}_{2}$}

\subsubsection{Intracellular generation of ${ }^{1} \mathrm{O}_{2}$}

Exponentially growing cells were washed with PBS and resuspended in this buffer at a concentration of $2.5 \times 10^{6}$ cells $\mathrm{ml}^{-1}$. RB [28], purified by gel chromatography [29], was added at different concentrations (between 1 and $0.1, \mathrm{M})$ to cell suspensions 10 min before irradiation to allow its penetration inside the cells. At various times of irradiation with filtered light (Osram XBO-150, $\lambda>$ $500 \mathrm{~nm}, 40 \mathrm{~W} \mathrm{~m}^{-2}$ ), $2 \times 10^{6}$ cells were collected and placed in culture. After 24 and $48 \mathrm{~h}$, cells were counted and aliquots of supernatant fluid were removed for the determination of the virus-associated reverse transcriptase (RT) activity.

\subsubsection{Extracellular generation of ${ }^{1} \mathrm{O}_{2}$}

Exponentially growing cells were washed twice with PBS and resuspended in PBS-D 20 at a concentration of $5 \times 10^{6}$ cells $\mathrm{ml}^{-1}$. Sensitox II (Poly RB, Hydron Laboratories, USA) was added to cells at a concentration of $10 \mathrm{mg} \mathrm{ml}^{-1}$. Aliquots of this suspension $(200 l)$ were placed in wells $(1.8$ $\mathrm{cm}^{2}$ ) of 24 well multidishes (Nunc, USA). A glass plate was inserted between samples and light source (Osram Xenophot HLX 64655, $85 \mathrm{~W} \mathrm{~m}^{-2}$ ) as cooling system and UV-IR filter. After various times of irradiation, cells were removed from the suspension and placed in culture. Percentages of viability were determined after $24 \mathrm{~h}$ and aliquots of supernatant were harvested after $48 \mathrm{~h}$ for detection of RT activity.

\subsection{CAT activity determination}

CAT assays were performed as described by Gorman et al. [33]. The CAT activity is expressed as the percentage of substrate conversion per $40 \mathrm{~g}$ of protein. The different reaction products were separated by thin layer chromatography and the spots corresponding to non-acetylated, mono-ace-tylated and diacetylated forms of chloramphenicol were revealed by autoradiography. They were cut from the thin layer chromatography plates and counted in a liquid scintillation counter.

\subsection{Reverse transcriptase (RT) assay}

The RT assay was performed according to Hoffman et al. [34]. Briefly, the virus was purified and concentrated by ultracentrifugation of supernatant fluids $\left(131000 \times \mathrm{g}\right.$ at $4{ }^{\circ} \mathrm{C}$ for $\left.2 \mathrm{~h}\right)$. Pellets were resuspended in 251 of TNE $(10 \mathrm{mM}$ Tris- $\mathrm{HCl}, 100 \mathrm{mM} \mathrm{NaCl}, 1 \mathrm{mM}$ ethylenediaminetetraacetic acid (EDTA) containing $0.1 \%$ Triton X-100 and left for $30 \mathrm{~min}$ on ice. The virus preparation $\left(\begin{array}{ll}10 & 1\end{array}\right)$ was incubated at $37{ }^{\circ} \mathrm{C}$ for $60-90 \mathrm{~min}$ with $40 \mathrm{l}$ of a solution containing $62.5 \mathrm{mM}$ Tris- $\mathrm{HCl} \mathrm{pH} 7.8,6.25$ $\mathrm{mM}$ dithiothreitol, $6.25 \mathrm{mM} \mathrm{MgCl} 2,180 \mathrm{mM} \mathrm{KCl}, 0.06 \%$ Triton X-100, $0.375 \mathrm{mM}$ glutathione, 0.325 mM EGTA (bis-(aminoethyl)-glycolether-N,N,N',N'-tetraacetic acid), $31 \mathrm{~g} \mathrm{ml}^{-1}$ bovine serum albumin (BSA), $2.5 \%$ ethylene glycol, $250 \mathrm{mU} \mathrm{ml}^{-1}$ poly(rA) $\bullet \mathrm{p}(\mathrm{dT})_{12}-18$ and $125 \mathrm{Ci} \mathrm{ml}^{-1}$ $\left[{ }^{3} \mathrm{H}\right]$ deoxythymidine. The DNA resulting from the extension reaction carried out by the RT was 
precipitated with $10 \%$ trichloroacetic acid (TCA) and filtered through $2.4 \mathrm{~m}$ Whatman GF-A filters. Filters were rinsed with $0.01 \mathrm{M}$ sodium pyrophosphate and dried with $95 \%$ ethanol and then counted by liquid scintillation. The relative errors on RT determination were estimated to be $\mathbf{\pm 5 \%}$.

\section{Results}

\subsection{Effect of ${ }^{1} \mathrm{O}_{2}$ on HIV-1 promoter activation in HeLa HIV-1 CAT cells}

In an attempt to determine whether an oxidative stress mediated by ${ }^{1} \mathrm{O}_{2}$ can represent the first step of the process leading to HIV-1 promoter activation, we used as cellular target an established cell line (HeLa HIV-1 CAT cells) carrying an integrated DNA cartridge containing the bacterial CAT gene under the control of HIV-1 LTR. A polyadenylation signal was introduced at the 3 ' end of the CAT gene allowing a correct transcription of the CAT gene. Initial experiments were designed to characterize the susceptibility of HeLa HIV-1 CAT cells to increasing doses of ${ }^{1} \mathrm{O}_{2}$ To determine the role of ${ }^{1} \mathrm{O}_{2}$ in heterologous promoter activation, two experimental systems were used: (i) a photosensitization reaction mediated by free $\mathrm{RB}$, which is a highly hydrosoluble chromophore generating ${ }^{1} \mathrm{O}_{2}$ with a good quantum yield [28], and (ii) a photosensitization reaction mediated by RB bound to beads (Sensitox II) also producing ${ }^{1} \mathrm{O}_{2}$ but with a lower quantum yield [30]. With the first experimental system, RB can penetrate the cells and initiate intracellular generation of ${ }^{1} \mathrm{O}_{2}$, whereas in the second system the chromophore can only remain outside the cell and generate ${ }^{1} \mathrm{O}_{2}$ extracellularly. As demonstrated in Figs. 1(A) and $1(\mathrm{~B}),{ }^{1} \mathrm{O}_{2}$ is highly cytotoxic for HeLa HIV-1 CAT cells. An increase in the irradiation time in the presence of RB (Fig. 1(A)) or Sensitox II (Fig. 1(B)) leads to a significant decrease in viability. No lethal effect was measured either in the absence of light or in the absence of photosensitizer. Irradiation of RB (1 $\mathrm{M})$ (Fig. 1(A)) rapidly produces a very low survival fraction (less than $1 \%$ after 30 min of irradiation) and consequently promotes heavy stress conditions. Survival as a function of irradiation time is less affected when HeLa HIV-1 CAT cells are irradiated in the presence of lower RB concentrations (Fig. 1(A)). In order to determine the lethal effect of extracellular generation of ${ }^{1} \mathrm{O}_{2}$, HeLa HIV-1 CAT cells attached to the bottom of culture dishes were covered with Sensitox II and irradiated for increasing times.

Survival to extracellular generation of ${ }^{1} \mathrm{O}_{2}$ is shown in Fig. 1(B). These stress conditions appeared to be somewhat similar to those recorded with $0.1 \mathrm{M}$ free $\mathrm{RB}$, i.e. $10 \%$ survival was obtained in both conditions after 30 min of irradiation. As shown in Figs. 1(A) and 1(B), the kinetics exhibit shoulders at short irradiation times and the rate of cell inactivation is increased when the buffer is prepared in $\mathrm{D}_{\mathrm{Z}} \mathrm{O}$ or decreased when cells are previously mixed with $80 \mathrm{M}$ ADPA which is an efficient ${ }^{1} \mathrm{O}_{2}$ quencher [31]. These results confirm that the phototoxic effect recorded in these experiments is due in large part to ${ }^{1} \mathrm{O}_{2}$.

The effect of ${ }^{1} \mathrm{O}_{2}$ on the activation of the HIV-1 promoter was estimated by measuring the CAT activity in cellular extracts of treated HeLa HIV-1 CAT cells. Figures 2(A) and 2(B) show that oxidative stress mediated by either intracellular or extracellular ${ }^{1} \mathrm{O}_{2}$ generation induces an increase in CAT activity in HeLa HIV-1 CAT cells $24 \mathrm{~h}$ after the stress. The CAT stimulation level depends on the oxidative stress intensity, exhibiting a maximum after $20 \mathrm{~min}$ of irradiation. Longer irradiation times, associated in both experimental systems with a lower survival fraction, reduce the level of CAT gene activation. Substitution of $\mathrm{H}_{2} \mathrm{O}$ by $\mathrm{D}_{\mathrm{Z}} \mathrm{O}$ or the addition of a ${ }^{1} \mathrm{O}_{2}$ quencher such as ADPA induce an increase or decrease respectively in the level of CAT gene activation, confirming that ${ }^{1} \mathrm{O}_{2}$ plays an important part in the mechanism leading to HIV-1 promoter activation (Fig. 2(B)). In order to demonstrate whether or not the activation of the HIV-1 promoter can be associated with the conversion of a latent to a productive infection, cells latently infected with HIV-1 (U1 and ACH-2) were subjected to oxidative stress mediated by ${ }^{1} \mathrm{O}_{2}$ in identical experimental conditions as those reported above, and the presence of infectious virus particles in cell supernatants was evaluated by measurement of RT 
activity.
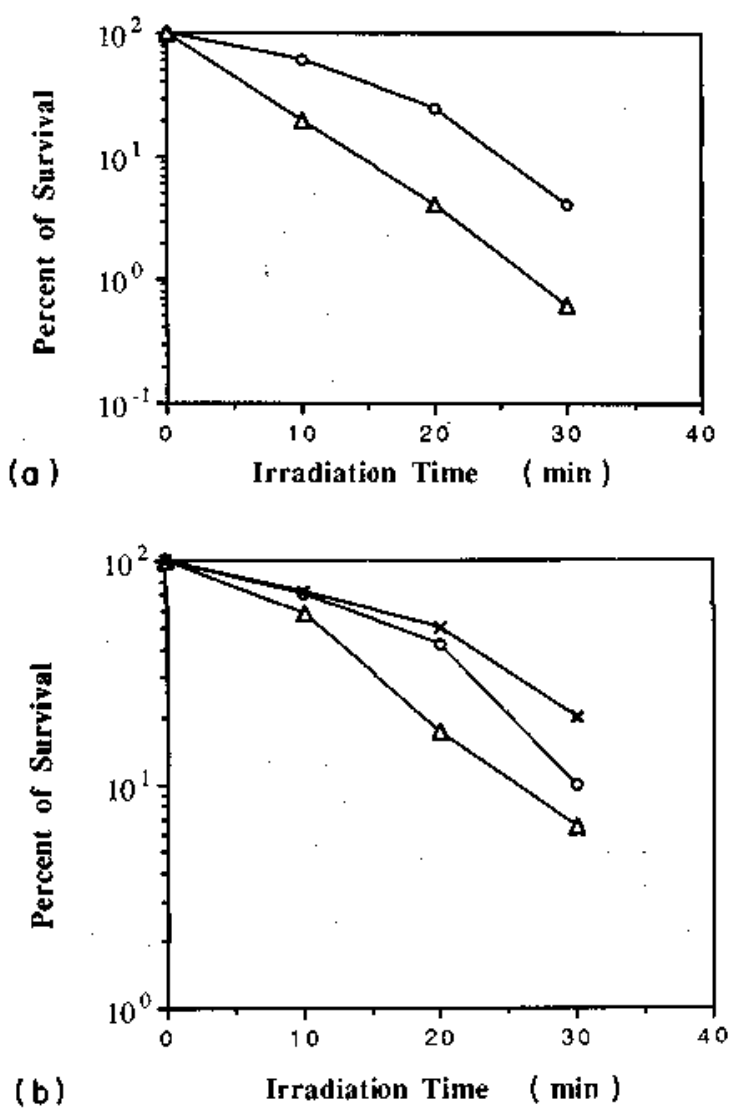

Fig. 1. Cytotoxic effect induced $24 \mathrm{~h}$ after photosensitization reaction on HeLa HIV-1 CAT cell line, (a) The photosensitization reaction was performed by mixing cells with free $R B$ and irradiating with visible light. Percentage survival $\left(\log _{10}\right)$ is plotted vs. the irradiation time: $\triangle, R B 1 \quad M ; O, R B \quad 0.1 \quad M$. (b) The pho-tosensitization reaction was performed using $R B$ bound to beads as photosensitizer. Percentage survival $\left(\log _{10}\right)$ is plotted vs. the irradiation time. Irradiation was performed in $\mathrm{PBS}-\mathrm{D}_{2} \mathrm{O}$ $(\triangle), P B S(O)$ and $P B S$ in the presence of 80 M ADPA $(x)$. 

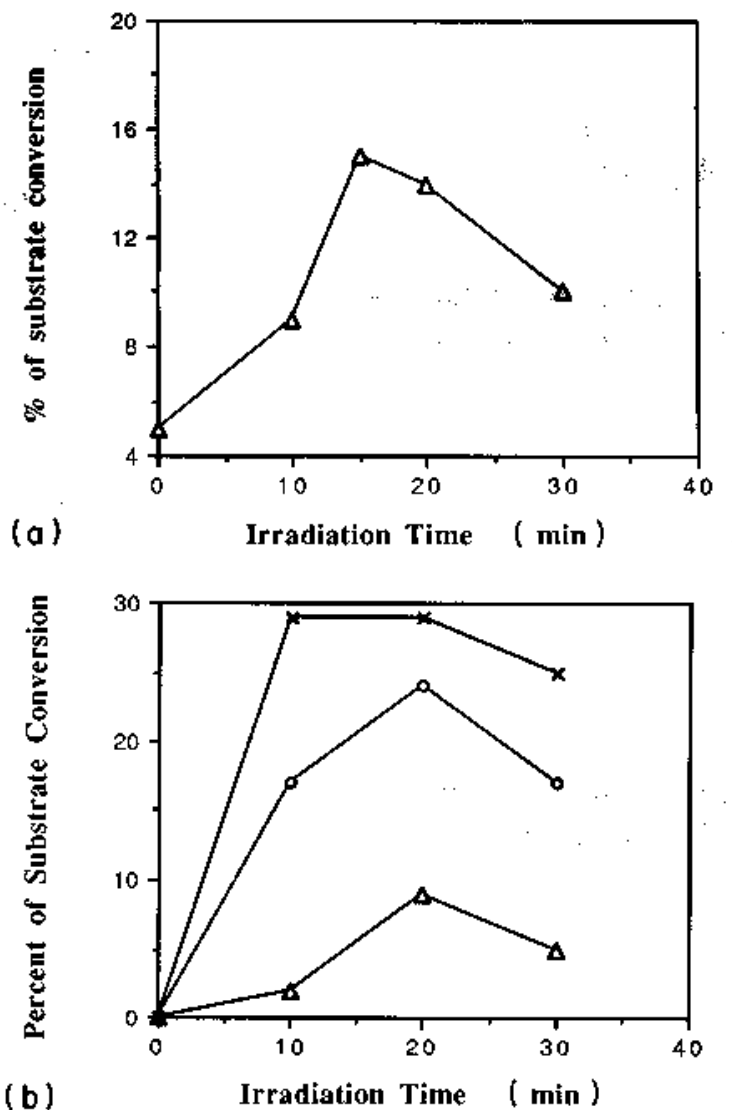

Fig. 2. HIV-1 promoter-leader sequence activation measured 24 h after photosensitization reaction on HeLa HIV-1 CAT cell line, (a) The photosensitization reaction was carried out in the presence of 0.1 ,M free RB. The percentage of substrate conversion is plotted vs. the irradiation time (min). (b) The pho-tosensitization reaction was carried out in the presence of $R B$ bound to beads. The percentage of substrate conversion is plotted vs. the irradiation time (min). The irradiation was performed after resuspension of cells in PBS- $D_{2} O(X), P B S(O)$ and PBS in the presence of 80 M ADPA ( $\left.\triangle\right)$.

\subsection{Effect of ${ }^{1} \mathrm{O}_{2}$ on HIV-1 reactivation from Ul and ACH-2 cells}

Two cell types latently infected by HIV-1 were used as targets of oxidative stress mediated by ${ }^{1} \mathrm{O}_{2} \mathrm{Ul}$ and $\mathrm{ACH}-2$ which are promonocyte and $\mathrm{T}$ lymphocyte cell lines respectively. The susceptibility of these two cell lines to oxidative stress mediated by ${ }^{1} \mathrm{O}_{2}$ was investigated by measuring cell survival. No lethal effect was detected either in the absence of light or in the absence of photosensitizer. As shown above for HeLa HIV-1 CAT cells, the photosensitization reaction mediated by either free RB (Fig. 3) or by RB bound to beads (Fig. 4) was highly cytotoxic for Ul and ACH-2 cells.

In both experimental conditions, lymphocytes appeared to be the most sensitive cells. When the photoreaction was mediated by free RB (Fig. 3), the survival was clearly dependent on the RB concentration, an identical survival being observed when Ul cells were treated with an RB concentration 1.6 times higher than that used for $\mathrm{ACH}-2$ cells.

HIV-1 reactivation was detected by measuring RT activity in the cell supernatant, 24 and $48 \mathrm{~h}$ after the photosensitization reaction mediated by free RB. As illustrated in Fig. 5, RT activities measured $24 \mathrm{~h}$ after the photoreaction were very low whatever irradiation time was chosen. However, $48 \mathrm{~h}$ after the photosensitization reaction, significant RT activities could be detected in the cell supernatants (Fig. 5). Two important features could be observed from RT measurements: (i) RT activities exhibited an optimal value as a function of the irradiation time, and (ii) for similar survival conditions, RT activities 
were somewhat higher for ACH-2 than for Ul cells. When Ul cells were treated with the lowest RB concentration $(0.25 \mathrm{M})$, the RT activity increased as a function of the irradiation time to reach its maximal value after $30 \mathrm{~min}$ of irradiation. These results clearly indicate that cells have to be cultivated at least $48 \mathrm{~h}$ after the photosensitization treatment to allow the release of virus particles in the supernatant and 30\% survival seems to correspond to the stress intensity leading to an optimal release of HIV-1. In these optimal stress conditions, the stimulation factor of the RT activities was around two for ACH-2 and three for Ul cells.

When ACH2 and U1 cells were exposed to the extracellular generation of ${ }^{1} \mathrm{O}_{2}$ mediated by RB bound to beads, no significant RT activity could be detected in cell supernatants, although cell viability was strongly affected by this oxidative stress.

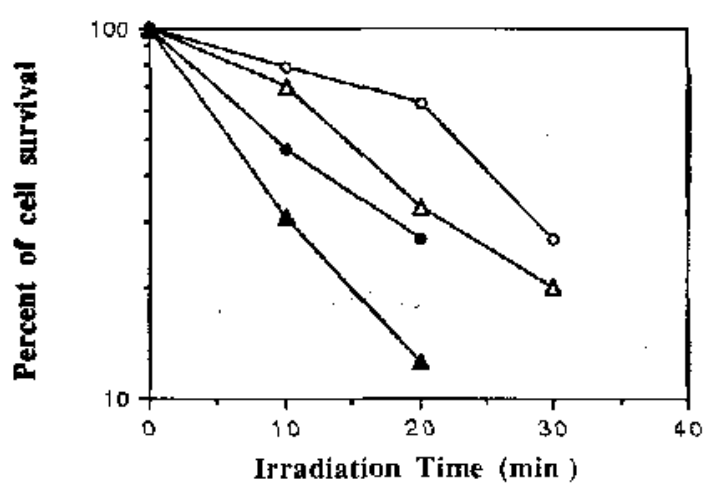

Fig. 3. Cytotoxic effect induced 24 h after a photosensitization reaction carried out in the presence of free $\mathrm{RB}$ on Ul and ACH-2 cell lines. Ul cells were irradiated in the presence of $0.25 \mathrm{MRB}(\mathrm{O})$ or 0.4 $M R B(\bullet)$. ACH-2 cells were irradiated in the presence of $0.25 M R B(\Delta)$ or $0.4 M R B(A)$.

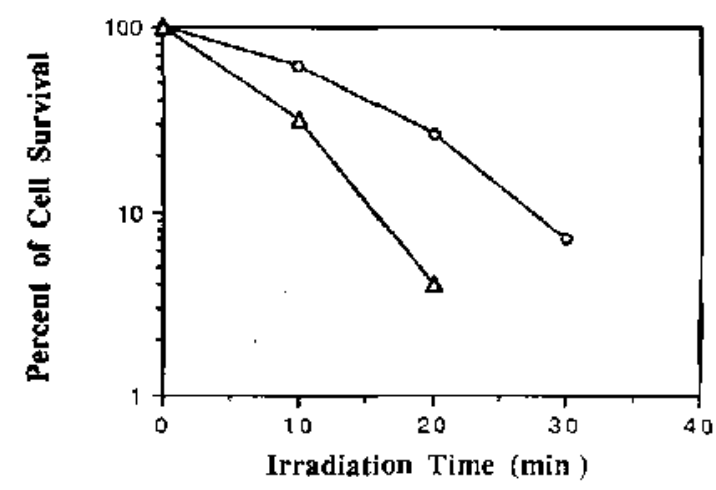

Fig. 4. Cytotoxic effect of photosensitization reaction mediated by $R B$ bound to beads on $U l(O)$ and ACH-2 ( $\Delta)$ cells. Percentage viability was determined 24 h after the oxidative stress. Percentage cell survival $\left(\log _{10}\right)$ is plotted vs. the irradiation time. 


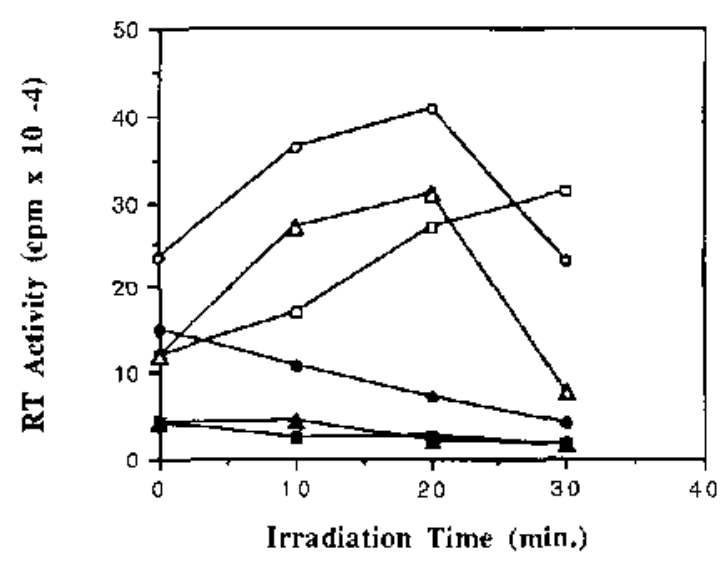

Fig. 5. Induction of HIV-1 reactivation mediated by photosen-sitization of Ul and ACH-2 cells. The photosensitization reactions were mediated by free $R B$ and visible light irradiation. Supernatant fluids were taken 24 and $48 \mathrm{~h}$ after the photo reaction. RT activities were determined after $24 \mathrm{~h}$ (filled symbols) and 48 h (open symbols). $O, A C H-2$ cells treated with $0.25 \mathrm{M} \mathrm{RB;} \Delta$, Ul cells treated with $0.4 \mathrm{MRB} ; \quad$, Ul cells treated with $0.25 \mathrm{MRB}$.

\section{Discussion}

During oxidative stress, various cellular genes whose major function is to contribute to cell protection are activated $[11,12,35]$. Recent reports demonstrate that photo-oxidative stress, mediated by porphyrin photosensitization, stimulates the expression of proteins belonging to the heat shock and glucose-regulated families (HSPs and GRPs), as well as the 32-34 kDa haemoxygenase stress protein $[36,37]$. The induction of these proteins appears to be regulated at the transcriptional level through cisacting sequences contained in the promoter of eukaryotic genes. In our work, we have unambiguously shown that singlet oxygen generated through RB, either free in solution or bound to beads, can lead to the induction of heterologous genes controlled by a viral promoter-leader sequence such as that involved in HIV-1 LTR. This transactivation of HIV-1 LTR has also been reported following oxidative stress mediated by hydrogen peroxide on epithelial cells [20] and human T cells [25]. In addition, UVmediated stress on epithelial cells [38] and transgenic mice [39] and psoralen adducts induced by 8 methoxypsoralen plus UVA in the skin of transgenic mice [40] can promote the transcriptional activation of a gene controlled by HIV-1 LTR. Heterologous promoter-leader sequence activation is a normal response to various stresses induced by oxygen activated species or by physical agents. In the case of a stress mediated by hydrogen peroxide, it has been shown that LTR transactivation occurs through the NF- $\mathrm{BB}$ transcription factor [25]. The hypothesis proposed involves the release of the inhibitory subunit I $\mathrm{B}$ from the complex with p65 and p50, generating an active NF- $\mathrm{B}$ factor which migrates to the nucleus allowing activation of genes having NF- $\mathrm{BB}$ responsive elements in their promoter such as HIV-1 LTR. It has recently been proposed that NF-kB is a transcription factor which has specialized in the organism to induce the rapid synthesis of defence and signalling proteins on exposure of cells to a wide variety of mostly pathogenic agents [41]. NF- $\mathrm{kB}$ induction and HIV-1 gene activation mediated by hydrogen peroxide and by other inducers, such as tumor necrosis factor- $\alpha$ (TNF- $\alpha$ ), phorbol ester, IL-1 (interleu-kine-1) and lectins, are blocked by N-acetyl cysteine (NAC), which is a well-characterized antioxidant agent [42]. It has been suggested that diverse agents with the ability to activate NF- $\mathrm{KB}$ may all act through a common mechanism involving synthesis of reactive oxygen intermediates (ROIs) [25]. These could serve as messengers mediating directly or indirectly the release of the inhibitory subunit I $\kappa$ B from NF- $\kappa$ B. The direct mechanism of NF- $\kappa$ B activation by ROIs would involve oxidative damage or controlled proteolytic degradation of the inhibitory subunit IкB and the indirect mechanism would involve a cellular response to oxidative damage with specific gene activation which, in turn, could lead to NF- $\mathrm{BB}$ induction and HIV-1 gene expression. The clear dosedependent effects observed in this work, between LTR induction and a decrease in cell viability, may suggest that a certain level of cell stress must be achieved to support a cellular stress response mediating HIV-1 gene activation. 
Several reasons can be put forward to indicate that DNA damage may be the first step in the pathway leading to HIV-1 LTR transactivation after oxidative stress. Firstly, DNA is the most shielded cellular element whose lesions are most susceptible to the triggering of a cellular response similar to the SOS response known in bacteria [43]. In E. coli, DNA damage such as pyrimidine dimers [44] or lesions induced by photosensitization mediated by proflavine [45] can trigger an SOS response which leads to the activation of numerous genes. Secondly, 102 is a strong nucleophile capable of damaging DNA. In cell-free systems, it reacts efficiently with DNA (for reviews, see refs. 13 and 14), generating predominantly 8-oxodeoxyguanine residues (8-oxodG) [46] and few strand breaks [15]. Inside cells, ${ }^{1} \mathrm{O}_{2}$ can be genotoxic when generated in the vicinity of DNA, e.g. by irradiation in the presence of a hydrophilic photosensitizer such as RB or with photosensitizers having DNA affinity [47, 48]. When

${ }^{1} \mathrm{O}_{2}$ is generated outside cells, its primary target is the membrane where it can initiate lipid peroxidation [49] or protein oxidation at the level of aromatic residues [50]. In a cell-free system, lipid radicals and/or lipid peroxides formed during the propagation step of lipid peroxidation and non-radical products generated by lipid peroxide decomposition can damage DNA [19]. For example, Park and Floyd [51] have shown that auto-oxidized lipids cause the formation of 8-oxodG in DNA and this reaction involves oxygen free radicals. In mammalian cells, extra-cellularly generated ${ }^{1} \mathrm{O}_{2}$ has also been shown to be genotoxic: mutations in Chinese hamster embryo cells [52], unscheduled DNA synthesis (UDS) in hamster tracheal epithelial cells [53] and sister chromatid exchange (SCE) in human lymphocytes [54] have been observed.

From the results presented above, it seems probable that DNA damage, induced by various types of cellular stress, is the first step in the pathway leading to the activation of several stress-induced genes, and also to heterologous promoters such as those from viruses when they are integrated in chromosomal DNA, e.g. the HIV-1 provirus LTR. This hypothesis is further supported by observations made by Stein et al. [55] who demonstrated that alterations of DNA structure are required for the induction of HIV-1 gene expression by UV irradiation.

In order to determine if oxidative stress mediated by ${ }^{1} \mathrm{O}_{2}$ can contribute to the conversion of a latent to a productive infection, leading to the development of acquired immune deficiency syndrome (AIDS), we used latently infected ACH-2 and Ul cells as targets. Exposure of these cells to ${ }^{1} \mathrm{O}_{2}$ generated intracellularly by RB photosensitization efficiently induced the reactivation of HIV-1. However, no viral production could be detected in cellular supernatants after extracellular generation of ${ }^{1} \mathrm{O}_{2}$, although the viability was strongly affected. This result was unexpected since oxidative stress mediated by extracellular ${ }^{1} \mathrm{O}_{2}$ has been shown to induce HIV-1 LTR transactivation in HeLa cells. Several hypotheses can explain this result. One or several steps which lead to viral particle release after LTR transactivation cannot occur in these stressed cells. For example, since cellular membranes are major targets of extracellular ${ }^{1} \mathrm{O}_{2}$, the envelopment step of the newly synthesized viral particles which should take place at the cellular membrane could be prevented by important membrane damage. This explanation would be compatible with the fact that CAT stimulation can be observed in HeLa HIV-1 CAT cells after exposure to extracellular ${ }^{1} \mathrm{O}_{2}$ since CAT gene expression does not require an intact membrane. Another hypothesis is that oxidative stress mediated by extracellular ${ }^{1} \mathrm{O}_{2}$ is not an efficient inducer of HIV-1 LTR transactivation in Ul and ACH-2 cells, although it has a lethal effect on these cells. It could then be postulated that the generation of ${ }^{1} \mathrm{O}_{2}$ outside monocytes or lymphocytes promotes cytotoxicity mainly due to membrane damage without any chromosomal DNA alteration. Because we suspect that DNA alteration is an important step in gene induction, this hypothesis could explain why, in these cells, no HIV-1 reactivation is detected. We can expect that promonocytes and lymphocytes have superior protection systems against oxidative stresses than epithelial cells such as HeLa cells. Indeed, promonocytes can themselves generate oxygen activated species when they are stimulated during inflammatory reactions and, like lymphocytes, accumulate in inflammatory foci where oxidant concentrations can be high [56].

From this work, we can conclude that oxidative stress, mediated by intracellular generation of ${ }^{1} \mathrm{O}_{2}$, is capable of inducing HIV-1 reactivation from latently infected lymphocytes and monocytes. This may be particularly relevant in vivo since latent virus is found in Langerhans cells of the skin [57], derived from monocyte-macrophage cell lineage, and can be subjected to intracellular ${ }^{1} \mathrm{O}_{2}$ production 
mediated by photosensitization. Indeed, these cells can be reached by UVA radiation which constitutes the major part of UV in sunlight, is the least harmful but the most penetrative. Endogenous photosensitizers such as porphyrins [58] and flav-ines [59] and pharmaceutical substances [60] used in the treatment of opportunist infections or cancers, which often occur in patients with AIDS, can be responsible for ${ }^{1} \mathrm{O}_{2}$ production. $\mathrm{HIV}-1$ reactivation from Langerhans cells subjected to oxidative stress could contribute to AIDS progression by impairing the antigen presentation function of the infected Langerhans cells and causing further immunosuppression or by resulting in increased infection of the adjacent $\mathrm{T}$ cell population of the skin [57].

\section{Acknowledgments}

This work was supported by grants from the National Fund for Scientific Research (NFSR, Brussels, Belgium). S.L-P. received a grant from the NFSR-Hippocrate International Fund, M.H. is a senior research assistant of NFSR and J.P. is a senior research associate of NFSR (Brussels, Belgium). We wish to thank Professor A. Van de Vorst for his continuous interest in our work.

\section{References}

[1] K. Gollnick, Type II photooxygenation reactions in solution, Adv. Photochem., 6 (1968) 1-122.

[2] C. Foote, Mechanistic characterization of photosensitized reaction, in G. Moreno, R. Pottier and T. G. Truscott (eds.), Photosensitization, Molecular, Cellular and Medical Aspects, 1988, Springer, Berlin, pp. 125-144.

[3] J. R. Kanofsky, H. Hoogland, R. Wever and S. J. Weiss, Singlet oxygen production by human eosinophils, /. Biol. Chem., 263 (1988) 9692-9696.

[4] B. M. Babior, R. S. Kipness and J. T. Cumutte, Biological defense mechanisms. The protection by leukocytes of superoxide, a potential bactericidal agent, J. Clin. Invest., 52 (1973) 741-744.

[5] B. Epe, E. Müller, R. P. Cunningham and S. Boiteux, Recognition by repair endonucleases of DNA damage induced by single oxygen and by photosensitization, in K. J. A. Davies (ed.), Oxidative Damage and Repair, Chemical, Biological and Medical Aspects, 1992, Pergamon, Oxford, pp. 326-330.

[6] J. M. McCord and I. Fridovich, Superoxide dismutase: an enzymic function for erythrocuprein (hemocuprin), J. Biol. Chem., 244 (1969) 6049-6055.

[7] B. N. Ames, Endogenous oxidative DNA damage, aging and cancer, Free Rad. Biol. Med. Commun., 7 (1960) 121-128.

[8] J. M. C. Gutteridge, T. Westmarck and B. Halliwell, Oxygen radical damage in biological systems, in B. Halliwell (ed.), Free Radicals, Aging and Degenerative Diseases, A. R. Liss, London, 1985, pp. 99-139.

[9] J. M. C. Gutteridge, S. K. Patterson, A. W. Segal and B. Halliwell, Inhibition of lipid peroxidation by the iron-binding protein lactoferrin, Biochem. J., 199 (1981) 259-261.

[10] S. Orrenius and G. Bellomo, Metabolic regulation in oxidative stress, in K. J. A. Davies (ed.), Oxidative Damage and Repair, Chemical, Biological and Medical Aspects, Pergamon, Oxford, 1992, pp. 449-547.

[11] C. J. Gomer, A. Ferrario, N. Hayashi, N. Rucker, B. Szirth and A. L. Murphee, Molecular, cellular and tissue response following photodynamic therapy, Laser Surg. Med., 8 (1988) 450-463.

[12] S. W. Ryter, A. Ferrario, A. M. R. Fisher, M. Luna, N. Rucker, S. Wong and C. J. Gomer, Photooxidative stress and photodynamic therapy, in K. J. A. Davies (ed.), Oxidative Damage and Repair, Chemical, Biological and Medical Aspects, Pergamon, Oxford, 1992, pp. 300-310.

[13] B. Epe, Genotoxicity of singlet oxygen, Chem.-Biol. Interact., 80 (1992) 239-260.

[14] J. Piette, Biological consequences associated with DNA oxidation mediated by singlet oxygen, J. Photochem. Photobiol. B: Biol, 11 (1992) 241-260.

[15] T. P. A. Devasagayam, S. Steenken, M. S. W. Obendorf, W. A. Schulz and H. Sies, Formation of 8-hydroxy(deoxy)guanosine and generation of strand breaks at guanine residues in DNA by singlet oxygen, Biochemistry, 30 (1991) 6283-6289. 
[16] D. Decuyper-Debergh, J. Piette and A. Van de Vorst, Singlet oxygen-induced mutations in M13 lac Z phage DNA, EMBO J., 6 (1987) 3155-3161.

[17] M. L. Wood, M. Dizdaroglu, A. Gajewski and J. M. Essigmann, mechanistic studies of ionizing radiation and oxidative mutagenesis: genetic effects of a single 8-hydroxyguanine (7-hydro-8-oxoguanine) residue inserted at a unique site in a viral genome, Biochemistry, 29 (1990) 7024-7032.

[18] B. Ranby and J. F. Rabeck (ed.), Singlet Oxygen. Reactions with Organic Compounds and Polymers, Wiley, London, 1978.

[19] C. E. Vaca, J. Wihelm and M. Harms-Ringdahi, Interaction of lipid peroxidation products with DNA. A review, Mutat. Res., 195 (1988) 137-149.

[20 ] S. Legrand-Poels, D. Vaira, J. Pincemail, A. Van de Vorst and J. Piette, Activation of human immunodeficiency virus type 1 by oxidative stress, AIDS Res., 12 (1990) 1389-1397.

[21] A. G. Dalgleish, P. C. L. Beverley, P. R. Clapham, D. H. Crawford, M. F. Greaves and R. A. Weiss, The CD4 (T4) antigen is an essential component of the receptor for the AIDS retrovirus, Nature (London), 312 (1984) 763-767.

[22] B. R. Cullen, Regulation of gene expression in the human immunodeficiency virus type 1, Adv. Virus Res., 40 (1991) 1-17.

[23] M. A. Garcia-Blanco and B. R. Cullen, Molecular basis of latency in pathogenic human viruses, Science, 245 (1991) 815 820 .

[24] D. Scott-Algara, F. Vuillier, M. Marasescu, J. de Saint-Martin and G. Dighiero, Serum levels of IL-2, IL-l $\alpha$, TNF- $\alpha$ and soluble receptor of IL-2 in HIV-1 infected patients, AIDS Res., 7 (1991) 381-385.

[25] R. Schreck, P. Rieber and P. A. Bauerle, Reactive oxygen intermediates as apparently widely used messengers in the activation of the NF- $\mathrm{BB}$ transcription factor and HIV-1, EMBO L, 10 (1991) 2247-2258.

[26] T. M. Folks, J. Justement, A. Kinter, S. Schnittman, J. Orenstein, G. Poli and A. S. Fauci, Characterization of a promonocytic clone chronically infected with HIV and inducible by 13-phorbol-12-myristate acetate, J. Immunol, 140 (1988) $1117-1122$

[27] K. A. Clouse, D. Powell, I. Washington, G. Poli, K. Strebel, W. Farrar, P. Barstad, J. Kovacs, A. S. Fauci and T. M. Folks, Monokine regulation of human immunodeficiency virus-1 expression in a chronically infected human T cell clone, J. Immunol, 142 (1989) 431-438.

[28] E. Gandin, Y. Lion and A. Van de Vorst, Quantum yield of singlet oxygen production by xanthene derivatives, Photochem. Photobiol, 37 (1983) 271-278.

[29] E. Gandin, Y. Lion and J. Piette, Purification of halogenated fluorescein derivatives by gel chromatography, j. Chromatogr., 249 (1982) 393-398.

[30] J. Paezkowskyiand and D. C. Neekers, Polymer-based sensitizer for the formation of singlet oxygen. New studies of polymeric derivatives of rose bengal, Macromolecules, 18 (1985) 1245-1253.

[31] B. A. Lindig, M. A. J. Rodgers and A. P. Schaap, Determination of the lifetime of singlet oxygen in $\mathrm{D}_{2} \mathrm{O}$ using $9,10-$ anthra-cenedipropionic acid, a water soluble probe, J. Am. Chem. Soc, 102 (1980) 5590-5593.

[32] M. A. J. Rodgers and P. T. Snowden, Lifetime of ${ }^{1} \mathrm{O}_{2}$ in liquid water as determined by time-resolved luminescence measurements, J. Am. Chem. Soc, 104 (1982) 5541-5543.

[33] C. M. Gorman, L. F. Moffat and B. H. Howard, Recombinant genomes which express chloramphenicol acetyltransferase in mammalian cells, Mol Cell. Biol, 2 (1982) 1044-1051.

[34] A. D. Hoffman, B. Banapour and J. A. Levy, Characterization of the AIDS-associated retrovirus reverse transcriptase and optimal conditions for its detection in virions, Virology, 147 (1985) 326-335.

[35] M. Ptashne, How transcriptional activators work, Nature (London), 335 (1988) 683-689.

[36] G. Storz, L. A. Tartaglia and B. N. Ames, Transcriptional regulator of oxidative stress-inducible genes: direct activation by oxidation, Science, 248 (1990) 189-194.

[37] C. J. Gomer, M. Luna, A. Ferrario and N. Rucker, Increased transcription and translation of heme oxygenase in Chinese hamster fibroblasts following photodynamic stress or Photofrin II incubation, Photochem. Photobiol., 53 (1991) $275-279$.

[38] K. Valerie, A. Delers, C. Bruck, C. Thiriart, H. Rosenberg, Ch. Debouck and M. Rosenberg, Activation of human immunodeficiency virus type 1 by DNA damage in human cells, Nature (London), 333 (1988) 78-81. 
[39] D. M. Frucht, L. Lamperth, E. Vicenzi, J. H. Belcher and M. A. Martin, Ultraviolet radiation increases HIV-long terminal repeat-directed expression in transgenic mice, AIDS Res., 7 (1991) 729-733.

[40] J. D. Morrey, S. M. Bourn, T. D. Bunch, M. K. Jackson, R. D. Sidwell, L. R. Barrows, R. A. Daynes and C. A. Rosen, In vivo activation of human immunodeficiency virus type 1

long terminal repeat by UV type A (UV-A) light plus psoralen and UV-B light in the skin of transgenic mice, J. Virol, 65 (1991) 5045-5051.

[41] P. A. Bauerle and D. Baltimore, in P. Cohen and J. G. Foulkes (eds.), Molecular Aspects of Cellular Regulation, Hormonal Control Regulation of Gene Transcription, Elsevier, Amsterdam, 1991, pp. $409^{\wedge} 32$

[42] M. Roderer, S. W. Ela, F. J. T. Staal and L. A. Herzenberg, TV-acetylcysteine: a new approach to anti-HIV therapy, AIDS Res., 8 (1992) 209-217.

[43] G. C. Walker, Inducible DNA repair systems, Ann. Rev. Biochem., 54 (1985) 425-457.

[44] P. Caillet-Fauquet, M. Defais and M. Radman, Molecular mechanism of induced mutagenesis. I. Replication of singlestranded UV-irradiated $\varphi$ X-174 DNA in intact and irradiated host cells, /. Mol. Biol, 117 (1977) 95-112.

[45] J. Piette, C. M. Calberg-Bacq and A. Van de Vorst, Pho-todynamic effect of proflavine on $\varphi$ X-174 bacteriophage, inactivation, mutagenesis and repair, Mol. Gen. Genet., 167 (1978) 95-103.

[46] R. A. Floyd, M. S. West, K. L. Eneff and J. E. Schneider, Methylene blue plus light mediates 8-hydroxyguanine formation in DNA, Arch. Biochem. Biophys., 273 (1989) 106-111.

[47] J. Piette, M. P. Merville and J. Decuyper, Damages induced in nucleic acids by photosensitization, Photochem. Photobiol, 44 (1986) 793-802

[48] B. Tudek, J. Laval and S. Boiteux, SOS-independent mutagenesis resulting from damages induced by methylene blue plus visible light in M13mpl8 phage DNA, Mol. Gen. Genet., in press.

[49] F. H. Doleiden, S. R. Fahrenholtz, A. A. Lamola and A. M. Trozzolo, Reactivity of cholesterol and some fatty acids towards singlet oxygen, Photochem. Photobiol, 20 (1974) 519-521.

[50] G. Jori, Photosensitized reactions of amino acids and proteins, Photochem. Photobiol, 21 (1975) $463-467$.

[51] J. W. Park and R. A. Floyd, Lipid peroxidation products mediate the formation of 8-hydroxydeoxyguanosine in DNA, Free Rad. Biol. Med., 12 (1992) 245-250.

[52] N. Gruener and M. P. Lockwood, Photodynamic mutagenicity in mammalian cells, Biochem. Biophys. Res. Commun., 90 (1979) 460-^65.

[53] L. J. Schiff, W. C. Eisenberg and K. Taylor, Evidence of DNA repair in organ cultures of hamster tracheal epithelium following exposure to gas phase singlet oxygen, Mutat. Res., 142 (1985) 41-44.

[54] D. Decuyper-Debergh, J. Piette, C. Laurent and A. Van de Vorst, Cytotoxic and genotoxic effects of extracellular generated singlet oxygen in human lymphocytes in vitro, Mutat. Res., 225 (1989) 11-14.

[55] B. Stein, H. J. Rahmsdorf, A. Shconthal, M. Buscher, H. Ponta and P. Herrlich, The UV induced signal transduction pathway to specific genes, UCLA Symposia on Molecular and Cellular Biology, 83 (1988) 1-14.

[56] H. J. Forman and M. Torres, Inflammation: an overview, in K. J. A. Davies (ed.), Oxidative Damage and Repair, Chemical, Biological and Medical Aspects, Pergamon, Oxford, 1990, pp. 636-641.

[57] G. Stingl, K. Rappersberger, E. Tschachler, S. Gartner, V. Groh, D. L. Mann, K. Wolf and M. Popovic, Langerhans cells in HIV-1 infection, J. Am. Acad. Dermatol, 22 (1990) 1210-1217.

[58] J. P. Keene, D. Kessel, E. J. Land, R. W. Redmont and T. G. Truscott, Direct detection of singlet oxygen sensitized by haemotoporphyrin and related compounds, Photochem. Photobiol, 43 (1986) 117-120.

[59] P. C. Joshi, Comparison of the DNA-damaging property of photosensitized riboflavin via singlet oxygen and superoxide radical mechanisms, Toxicol. Lett., 26 (1985) 211-217.

[60] I. E. Kochevar, Mechanisms of drug photosensitization, Photochem. Photobiol, 45 (1987) 891-895. 